Food Chemistry

Vol. 88, Issue 3 , December 2004, Pages 389-395

http://dx.doi.org/10.1016/j.foodchem.2004.01.053

(c) 2004 Elsevier Ltd. All rights reserved.
Archimer, archive institutionnelle de l'Ifremer http://www.ifremer.fr/docelec/

\title{
Relative contribution of calpain and cathepsins to protein degradation in muscle of sea bass (Dicentrarchus labrax L.)
}

\author{
Christine Delbarre-Ladrat ${ }^{\star, 1}$, Véronique Verrez-Bagnis ${ }^{1}$, Joëlle Noël ${ }^{1}$ and Joël Fleurence ${ }^{1,2}$
}

1 IFREMER, DRV-VP, BP21105, 44311 Nantes Cedex 3, FRANCE

2 Present address: UFR Sciences et Techniques, ISOMER, BP 92208, 44322 Nantes Cedex 3 , FRANCE

*: Corresponding author : Tel.: +33-2-40-37-40-00; fax: +33-2-40-37-40-71; email: cladrat@ifremer.fr

\begin{abstract}
:
The effects of a milli $(\mathrm{m})$-calpain isolated from the white muscle of sea bass (Dicentrarchus labrax $\mathrm{L}$ ) and commercial cathepsins $\mathrm{B}, \mathrm{D}$ and $\mathrm{L}$, used in combination on the myofibrillar and sarcoplasmic proteins were examined. Protein digestion was first performed by the endogenous $\mathrm{m}$-calpain, during 2 $\mathrm{h}$ before the addition of a mixture of cathepsins $B, D$ and $L$ and a further incubation up to $22 \mathrm{~h}$. Calpain degraded a $27 \mathrm{kDa}$ sarcoplasmic component as well as myosin heavy chain, $\alpha$-actinin, desmin and a $32 \mathrm{kDa}$ component from the myofibrillar fraction. A $97 \mathrm{kDa}$ component and the assumed creatine kinase-aldolase doublet were degraded during the incubation of sarcoplasmic proteins with the cathepsin mixture while, among the myofibrillar proteins, myosin, actin, tropomyosin, and the $22 \mathrm{kDa}$ component were digested by the same enzymatic preparation. Myofibril-bound $\alpha$-actinin and tropomyosin were released into the soluble fraction by $\mathrm{m}$-calpain and the cathepsins mixture. Some smaller fragments were also produced. This appears to be the result of the cumulative action of each protease, as already investigated in our previous studies, except for the degradation of the sarcoplasmic $97 \mathrm{kDa}$ component. It was only degraded if the cathepsins were mixed; this indicates that the three cathepsins functioned synergistically on muscle proteins. No difference in the proteolytic effect of cathepsins was observed, whether calpain was acting first or not. This work showed that calpain did not modify any muscle protein prior to later hydrolysis by the catheptic proteinases.
\end{abstract}

Keywords: Neutral calcium-dependent protease; Cathepsins; Proteolysis; Fish muscle; Postmortem aging 


\section{Introduction}

Despite awareness that proteolysis plays a critical role in post mortem aging of muscle resulting in tenderization, a clear understanding of the mechanisms responsible remains elusive. In contrast to mammalian muscles for which tenderness is beneficial to meat quality, tenderization of fish muscle results in its deterioration. The initial steps in this process include endogenous hydrolytic reactions brought about by enzymes. The role of cathepsins and calpains in the post mortem proteolysis of fish muscle has received limited attention compared to the extent of studies on these enzymes in mammalian tissue.

Calpains (neutral calcium-dependent proteases) and cathepsins (lysosomal proteases) are the two major degradative pathways usually described as involved in the post mortem aging process. Two ubiquitous forms of calpains exist within the cells: micro( $\mu)$-calpain, and milli(m)-calpain. Fish muscle calpains have received only little attention compared to mammalian counterparts (Geesink, Morton, Kent \& Bickerstaffe, 2000 ; Toyohara \& Makinodan, 1989 ; Jiang, Wang \& Chen, 1991). It has been shown that, in sea bass muscle, they are differently expressed depending on the season of the year (Ladrat, Chaplet, VerrezBagnis, Noël \& Fleurence, 2000). On the other hand, cathepsins B, D, L and H are the major cathepsins within the fish lysosomes (Aoki, Yamashita \& Ueno, 2000) ; some of them have been studied for their enzymatic features (Lee, Chen \& Jiang, 1993 ; Jiang, Lee \& Chen, 1994 ; Goldman-Levkovitz, Rimon \& Rimon, 1995 ; Heu, Kim, Cho, Godber \& Pyeun, 1997) and for their ability to degrade muscle proteins (Jiang, Wang \& Chen, 1992 ; Aoki \& Ueno, 1997 ; Aranishi, Ogata, Hara, Osatomi \& Ishihara, 1998).

It would be expected that the respective action of each protease is possibly affected by the other proteases. In particular, endoproteases could degrade proteic substrates to be further proteolysed by other proteases. Moreover, calpains have been believed to initiate the proteolytic degradation of myofibrils by causing a little hydrolysis on proteins making them more susceptible to other proteases (Goll, Thompson, Taylor \& Christiansen, 1992 ; Lamare, Taylor, Farout, Briand \& Briand, 2002 ; Papa, Alvarez, Verrez-Bagnis, Fleurence \& Benyamin, 1996).

Our objective in the current study, therefore, was to improve our understanding of the mechanisms involved in post mortem deterioration of fish muscle and to acquire an insight into the concept of the synergistic effect of calpains and cathepsins. In our previous studies, the involvement of calpain and cathepsins in the proteolysis of sea bass white muscle during refrigerated storage was investigated using enzymes one by one (Verrez-Bagnis, Ladrat, Noelle \& Fleurence, 2002 ; Ladrat, Verrez-Bagnis, Noël \& Fleurence, 2003). In this work, these enzymes are used in combination.

\section{Material and methods}

\section{Fish}

Live sea bass (Dicentrarchus labrax L.) were purchased from a local sea farm in Vendée (France) and killed by beheading. In a cold room, viscera and skin were removed and white muscle was recovered.

\section{Protein preparations for enzymatic digestions}

Sarcoplasmic proteins were extracted by homogenising the sea bass muscle frozen at death at $-80^{\circ} \mathrm{C}$ in 4 volumes $(\mathrm{w} / \mathrm{v})$ of water containing $1 \mathrm{mM}$ EDTA. The supernatant recovered after two centrifugations at $10000 \mathrm{~g}, 4^{\circ} \mathrm{C}$ for 15 minutes was used as the sarcoplasmic preparation. The protein content $(9.3 \mathrm{mg} / \mathrm{ml})$ was determined by Bradford assay (Bradford, 1976) using Bio-Rad reagent (Bio-Rad, Ivry-sur-Seine, France), and bovine serum albumin as the standard. 
Myofibrils were isolated from fresh sea bass muscle according to the procedure of Wang (Wang, 1982), suspended in $50 \%(\mathrm{v} / \mathrm{v})$ glycerol and stored at $-20^{\circ} \mathrm{C}$ until use. Protein content was estimated at $12.5 \mathrm{mg} / \mathrm{ml}$ by Bradford assay. When needed, $800 \mu \mathrm{l}$ of this preparation were taken and centrifuged three times at 4000 rpm for 15 minutes at ambient temperature. Each time, the pellet was washed in $1 \mathrm{ml}$ water. The final pellet was used directly for myofibrillar protein digestion.

\section{Proteases preparation}

Cathepsin L from Paramecium tetraucelia was purchased from CALBIOCHEM (Merck Eurolab, Fontenay-sous-bois, France). Cathepsin B (Ref C6286) and cathepsin D (Ref C3138), both from bovine spleen, were from SIGMA (Saint-Quentin-Fallavier, France). No fish cathepsins were commercially available, but most data on the catalytic activity and molecular properties of cathepsins are consistent regardless of the source (Gildberg, 1988 ; Yamashita \& Konagaya, 1990a ; Yamashita \& Konagaya, 1990b). Milli-calpain was purified from sea bass muscle as previously described (Ladrat, Verrez-Bagnis, Noel \& Fleurence, 2002).

\section{Proteolytic digestions}

Digestions were performed at $25^{\circ} \mathrm{C}$ during two hours with m-calpain and then a mixture of the three above cathepsins was added. Highly purified m-calpain $(18.6 \mu \mathrm{g} / \mathrm{ml}$ enzyme) was added to sarcoplasmic or myofibrillar proteins to a final ratio of $1 / 500(\mathrm{w} / \mathrm{w})$ in the presence of $5 \mathrm{mM} \mathrm{CaCl}$ and $5 \mathrm{mM} \beta$-mercaptoethanol in $50 \mathrm{mM}$ Tris buffer $\mathrm{pH}$ 7. After two hours of incubation, 1 volume of $50 \mathrm{mM}$ citrate phosphate buffer $\mathrm{pH} 5.5$ was added in order to decrease the $\mathrm{pH}$ to 5.5 and the cathepsins mixture containing $35 \mu \mathrm{g}$ cathepsin $\mathrm{D}$ (final 19 $\mu \mathrm{g} / \mathrm{ml}$ ), $10 \mu \mathrm{g}$ cathepsin B (final $5.4 \mu \mathrm{g} / \mathrm{ml}$ ) and $2 \mu \mathrm{g}$ cathepsin L (final $1.1 \mu \mathrm{g} / \mathrm{ml}$ ) in $50 \mathrm{mM}$ citrate phosphate buffer was added. Incubations lasted up to $22 \mathrm{~h}$. Aliquots were sampled at 0 30 min and 1.5 hour (corresponding to the action of calpain) and at $2 \mathrm{~h}-3 \mathrm{~h}-5 \mathrm{~h}$ and $22 \mathrm{~h}$ total incubation duration (corresponding to the digestion by the mixture of cathepsins).

Three different treatments were performed in this combined experiment with calpain and cathepsins: the first one (treatment A) with both calpain and cathepsins mixture as indicated above, the second one (treatment B) with calpain and addition of $50 \mathrm{mM}$ citrate phosphate buffer $\mathrm{pH} 5.5$ instead of cathepsins, and the last one (treatment $\mathrm{C}$ ) with $50 \mathrm{mM}$ Tris buffer $\mathrm{pH}$ 7 instead of calpain with addition of the mixture of the cathepsins. A negative control (D) was carried out without any enzyme but with the appropriate buffer instead. Each digestion was done and analysed twice.

Aliquots from the sarcoplasmic protein digestions were removed at specific intervals, mixed with $4 \mathrm{x}$ concentrated SDS-containing tracking dye and immediately heated for $3 \mathrm{~min}$ at $100^{\circ} \mathrm{C}$. To follow the breakdown of myofibrillar proteins, a sampled aliquot was centrifuged at $4000 \mathrm{rpm}$, at room temperature for $15 \mathrm{~min}$ in the presence of inhibitors to stop the reaction (0.01 mM E64, $0.01 \mathrm{mM}$ pepstatin A) and insoluble material precipitated. The pellet was dissolved in the same volume as initial aliquot of $40 \mathrm{mM}$ Tris buffer containing $8 \mathrm{M}$ urea and $4 \mathrm{x}$ SDS-containing tracking dye was added before boiling for $3 \mathrm{~min}$. The remaining supernatant containing proteins released from myofibrils was added to $4 \mathrm{x}$ concentrated SDScontaining tracking dye and boiled.

\section{SDS-PAGE}

SDS-PAGE was carried out in a Mini-protean dual slab cell (Bio-Rad) according to the method of Laemmli (Laemmli, 1970) using 4-20\% polyacrylamide gradient gels. $5 \mu \mathrm{l}$ of sample from the digestion of sarcoplasmic proteins, $5 \mu \mathrm{l}$ of sample prepared from the pellet of digested myofibrillar proteins and $10 \mu \mathrm{l}$ from the corresponding supernatant were loaded. 
Molecular weight markers were from Bio-Rad (Broad Precision recombinant standards) or from SIGMA (SDS-6H and SDS-7 mixture: Myosin $205 \mathrm{kDa}$, ß-galactosidase $116 \mathrm{kDa}$, phosphorylase b $97.4 \mathrm{kDa}$, bovine albumin $66 \mathrm{kDa}$, egg albumin $45 \mathrm{kDa}$, glyceraldehyde-3phosphate dehydrogenase $36 \mathrm{kDa}$, carbonic anhydrase $29 \mathrm{kDa}$, trypsinogen $24 \mathrm{kDa}$, trypsin inhibitor $20.1 \mathrm{kDa}, \alpha$-lactalbumin $14.2 \mathrm{kDa}$ ). Average molecular weights were estimated from several analysed gels.

After migration, gels were subsequently stained with Coomassie Brilliant Blue R250 or blotted overnight onto a membrane.

\section{Western blots of structural proteins}

Electrophoresis gels were blotted overnight at $15^{\circ} \mathrm{C}$ onto a $0.45 \mu \mathrm{m}$ nitrocellulose membrane (Bio-Rad) at $30 \mathrm{~V}$ using a Mini-Transblot Cell (Bio-Rad) with transfer buffer containing 150 mM glycine, 20 mM Tris, $20 \%$ methanol and $0.01 \%$ SDS. Membranes were saturated with 8 $\%$ skimmed milk prepared in $0.9 \% \mathrm{NaCl}$, washed with phosphate buffered saline (PBS) (137 $\mathrm{mM} \mathrm{NaCl}, 2.7 \mathrm{mM} \mathrm{KCl}$ in $10 \mathrm{mM}$ phosphate buffer $\mathrm{pH}$ 7.4) containing $0.05 \% \mathrm{v} / \mathrm{v}$ Tween 20 and further incubated for 2 hours at room temperature with primary rabbit antibodies in $0.9 \%$ $\mathrm{NaCl}$. After being washed in PBS with $0.05 \% \mathrm{v} / \mathrm{v}$ Tween 20, blots were incubated with secondary goat anti-rabbit IgG alcaline phosphatase conjugate diluted with $0.9 \% \mathrm{NaCl}$ containing $5 \%$ bovine serum albumin. Enzymatic detection was carried out using nitroblue tetrazolium / 5-bromo-4-chloro-3-indolyl phosphate (NBT/BCIP) as the substrate resulting in brown red-coloured bands on the membrane. Polyclonal anti- $\alpha$-actinin produced in the laboratory (1/300 dilution) was used as primary antibody on sarcoplasmic and myofibrillar proteins digestions while polyclonal anti-desmin (SIGMA, Ref D8281, 1/200 dilution) and polyclonal anti-tropomyosin (SIGMA, Ref T3651, 1/200 dilution) were used as primary antibodies for the in vitro proteolysis of myofibrillar proteins only.

\section{Image analysis}

The Coomassie Blue stained gels as well as the immunoblots were photographed with a CCD camera system (Image Master VDS-CL, Amersham Biosciences) and analysed with 1D-Elite software (Amersham Biosciences).

\section{Results}

\section{Sarcoplasmic proteins combined digestion}

In this experiment in which both types of proteases were used in combination, the only modification on sarcoplasmic proteins caused by calpain was observed for the $27 \mathrm{kDa}$ band which was fragmented into a band of very close molecular weight as previously described (Figure 1A) (Verrez-Bagnis et al., 2002). But cathepsins were able to degrade the $97 \mathrm{kDa}$ protein and the creatine kinase-aldolase assumed doublet (41-39 doublet) as it was identified by comparisons of fish proteins pattern in a previous article (Ladrat et al., 2003). In this area, the real protein affected is not clear because of the existence of huge bands. A fragment around $34 \mathrm{kDa}$ was increasing. Two fragments (25 and $20.5 \mathrm{kDa}$ ) were produced during the incubation with cathepsins. A $21.5 \mathrm{kDa}$ component was degraded. A $20.5 \mathrm{kDa}$ band was appearing in each experiment performed even when no enzyme was added giving evidence for an unidentified and uncontrolled occurring mechanism (Figure 1D).

Comparing results from Figure 1C and 1A possibly indicated the synergistic effect of calpain and cathepsins. Treatment without the calpain but with the mixture of cathepsins (Figure 1C) showed that the $97 \mathrm{kDa}$ component, the creatine kinase-aldolase doublet and the $21.5 \mathrm{kDa}$ proteins were degraded while the $34 \mathrm{kDa}$ and $24 \mathrm{kDa}$ band were also increasing. Treatment $\mathrm{B}$ together with negative control on Figure 1 indicated that the cathepsins are really responsible for these changes in protein patterns. 
$\alpha$-actinin present in the soluble fraction of muscular proteins was affected neither by calpain nor by cathepsins (Figure 2) confirming the already observed stability in relation to each cathepsin action (Ladrat et al., 2003).

\section{Myofibrillar protein digestion}

During in vitro proteolysis of myofibrillar proteins by calpain followed by cathepsins (Figure 3), partial degradation of myosin heavy chain (MHC) was observed all over the incubation. Two fragments (140 and $78 \mathrm{kDa}$ ) were generated by the action of calpain and subsequently degraded during the incubation with the mixed cathepsins. Calpain left actin intact before its degradation by cathepsins. Tropomyosin ( $34 \mathrm{kDa}$ ) was degraded only after the addition of the cathepsins. Calpain caused the loss of the $32 \mathrm{kDa}$ component (assumed to be troponin $\mathrm{T}$ ). Cathepsins cleaved the $22 \mathrm{kDa}$ band. Three other fragments appeared during the incubation with cathepsins: 68, 33 and $30 \mathrm{kDa}$. At the end of the incubation, all the proteins were completely hydrolysed and only a smear was visible on the lane. The comparison of the different treatment groups and control (Figure 3) showed that the above mentioned changes are due to calpain and/or to cathepsins as indicated and not to an unidentified and uncontrolled factor as it was the case for the sarcoplasmic proteins. Moreover, no difference was observed in the changes induced by cathepsins between the experiments in which calpain was acting first (treatment A, Figure 3A) or not (treatment C, Figure 3C), thus suggesting mcalpain did not modify myofibrillar proteins in a manner that rendered them more susceptible to the action of cathepsins.

As we can see in Figure 4II, $\alpha$-actinin was degraded into a set of fragments by calpain (90 $\mathrm{kDa}, 80,71$, and $37 \mathrm{kDa}$ ). They were all degraded subsequently by the cathepsins but these latter proteases produced also a $99 \mathrm{kDa}$ and a $104 \mathrm{kDa}$ fragment from the remaining undegraded $\alpha$-actinin subunit. Tropomyosin remained unchanged upon action of calpain as we can see on immunoblots on pellets (Figure 4III). It was afterwards degraded into a $32 \mathrm{kDa}$ fragment by cathepsins (Figure 4III). Control showed only a slight decrease in the probed band intensity without any degradation (data not shown). Desmin was rapidly and highly degraded by calpain (Figure 4IV) with degradation fragments visible as early as the beginning of incubation. No desmin was visible in the second sampling. This result confirmed the previous observation of Verrez-Bagnis et al. (2002).

Some proteins were released from myofibrils into the supernatant before being completely degraded during treatment A ; in particular, two fragments of 62 and $54 \mathrm{kDa}$ were released into the soluble fraction (Figure 5I) by cathepsins. No visible difference in the action of the cathepsins was observed between treatments involving first action of calpain and the treatment without calpain (data not shown). Intact $\alpha$-actinin and some of its breakdown fragments were released in the soluble fraction (Figure 5II). Calpain and cathepsins were able to liberate tropomyosin from myofibrils into the soluble fraction but only cathepsins could degrade it (Figure 5III).

The observed action of the mixture of the all three cathepsins at $\mathrm{pH} 5.5$ appears to be the result of the cumulative action of each cathepsin studied in a previous work (Ladrat et al., 2003) except for the $97 \mathrm{kDa}$ sarcoplasmic component which was broken down only by the mixture of the three cathepsins all together.

\section{Conclusion}

Our previous results showed that MHC, $\alpha$-actinin, desmin, actin, troponin $\mathrm{T}$, tropomyosin and other non identified protein bands can be degraded by cathepsins D, B, or L (Ladrat et al., 2003). This work showed that when these three cathepsins are mixed, each of the above proteins is also degraded. In addition, a $97 \mathrm{kDa}$ component was degraded by the mixture but not by each cathepsin taken apart from the others. In this case, the three cathepsins act in 
synergy. When the cathepsin B, D and L mixture acted after the action of calpain, no difference was observed with the tratment without calpain suggesting calpain did not modify proteins and did not make them more susceptible to the further degradation by cathepsins as it was hypothesized by (Goll et al., 1992 ; Lamare et al., 2002 ; Papa et al., 1996). A combined incubation in which the myofibrils were first hydrolyzed by m-calpain then later subjected to a lysosomal extract has already been studied by Whipple and Koohmaraie (Whipple \& Koohmaraie, 1991). It also led the authors to the conclusion that m-calpain did not alter any myofibrillar protein to be later hydrolyzed by the acidic proteinases.

In vitro degradation of muscle proteins by isolated or purified proteases is far more extensive than the degradation occurring with normal postmortem storage. Attempts in vitro to reproduce events in vivo can never be absolute because of reaction conditions (temperature, $\mathrm{pH}$, enzyme:substrate ratio). In particular, an accurate enzyme:substrate ratio selection close to the physiological ratio is complicated by the presence of naturally occurring inhibitors. Nevertheless, our analysis substantiates the idea that calpain and cathepsins do not function synergistically in post mortem muscles but does not rule out the action of calpain in the early phases of post mortem aging followed by the cathepsins action. 


\section{Reference list}

Aoki, T., \& Ueno, R. (1997). Involvement of cathepsins B and L in the post-mortem autolysis of mackerel muscle. Food Research International, 30(8), 585-591.

Aoki, T., Yamashita, T., \& Ueno, R. (2000). Distribution of cathepsins in red and white muscles among fish species. Fisheries Science, 66(4), 776-782.

Aranishi, F., Ogata, H., Hara, K., Osatomi, K., \& Ishihara, T. (1998). Susceptibility of opioid peptides and myofibrillar proteins to carp cathepsin L. Journal of Agricultural and Food Chemistry, 46(2), 388-392.

Bradford, M. M. (1976). A rapid and sensitive method for the quantification of microgram quantities of protein utilizing the principle of protein-dye binding. Analytical Biochemistry, 72, 248-254.

Geesink, G., Morton, J., Kent, M., \& Bickerstaffe, R. (2000). Partial purification and characterization of Chinook salmon (Oncorhynchus tshawytscha) calpains and an evaluation of their role in postmortem proteolysis. Journal of Food Science, 65(8), 1318-1324.

Gildberg, A. (1988). Aspartic proteinases in fishes and aquatic invertebrates. Comparative Biochemistry and Physiology, 91B(3), 425-435.

Goldman-Levkovitz, S., Rimon, A., \& Rimon, S. (1995). Purification, properties and specificity of cathepsin D from Cyprinus carpio. Comparative Biochemistry and Physiology, 112B(1), 147-151.

Goll, D. E., Thompson, V. F., Taylor, R. G., \& Christiansen, J. A. (1992). Role of the calpain system in muscle growth. Biochimie, 74, 225-237.

Heu, M. S., Kim, H. R., Cho, D. M., Godber, J. S., \& Pyeun, J. H. (1997). Purification and characterization of cathepsin L-like enzyme from the muscle of anchovy Engraulis japonica. Comparative Biochemistry and Physiology, 118B(3), 523-529.

Jiang, S.-T., Lee, J.-J., \& Chen, H.-C. (1994). Purification and characterization of cathepsin B from ordinary muscle of mackerel (Scomber australasicus). Journal of Agricultural and Food Chemistry, 42, 1073-1079.

Jiang, S.-T., Wang, J.-H., \& Chen, C.-S. (1991). Purification and some properties of calpain II from Tilapia muscle (Tilapia nilotica x Tilapia aurea). Journal of Agricultural and Food Chemistry, 39, 237-241.

Jiang, S.-T., Wang, Y.-T., \& Chen, C.-S. (1992). Lysosomal enzyme effects on the postmortem changes in tilapia (Tilapia nilotica $\mathrm{x}$ T. aurea) muscle myofibrils. Journal of Food Science, 57(2), 277-279.

Ladrat, C., Chaplet, M., Verrez-Bagnis, V., Noël, J., \& Fleurence, J. (2000). Neutral calciumactivated proteases from European sea bass (Dicentrarchus labrax L.) muscle: polymorphism and biochemistry studies. Comparative Biochemistry and Physiology, 125B, 83-95.

Ladrat, C., Verrez-Bagnis, V., Noel, J., \& Fleurence, J. (2002). Milli-calpain from sea bass 
(Dicentrarchus Labrax) white muscle: purification, characterization of its activity and activation in vitro. Marine Biotechnology, 4(1), 51-62.

Ladrat, C., Verrez-Bagnis, V., Noël, J., \& Fleurence, J. (2003). In vitro proteolysis of myofibrillar and sarcoplasmic proteins of white muscle of sea bass (Dicentrarchus labrax L.): effects of cathepsins B, D and L. Food Chemistry, 81, 517-525.

Laemmli, U. K. (1970). Cleavage of structural proteins during the assembly of the head of bacteriophage T4. Nature, 227, 680-685.

Lamare, M., Taylor, R. G., Farout, L., Briand, Y., \& Briand, M. (2002). Changes in proteasome activity during postmortem aging of bovine muscle. Meat Science, 61, 199-204.

Lee, J.-J., Chen, H.-C., \& Jiang, S.-T. (1993). Purification and characterization of proteinases identified as cathepsins $\mathrm{L}$ and L-like (58 kDa) proteinase from mackerel (Scomber australasicus). Bioscience, Biotechnology and Biochemistry, 57(9), 1470-1476.

Papa, I., Alvarez, C., Verrez-Bagnis, V., Fleurence, J., \& Benyamin, Y. (1996). Post mortem release of fish white muscle $\alpha$-actinin as a marker of disorganisation. Journal of Science and Food Agriculture, 72(1), 63-70.

Toyohara, H., \& Makinodan, Y. (1989). Comparison of calpain I and calpain II from carp muscle. Comparative Biochemistry and Physiology, 92B(3), 577-581.

Verrez-Bagnis, V., Ladrat, C., Noelle, J., \& Fleurence, J. (2002). In vitro proteolysis of european sea bass (Dicentrarchus labrax) myofibrillar and sarcoplasmic proteins by an endogenous m-calpain. Journal of the Science and Food Agriculture, 82, 12561262.

Wang, K. (1982). Purification of titin and nebulin. Methods in Enzymology, 85, 264-274.

Whipple, G., \& Koohmaraie, M. (1991). Degradation of myofibrillar enzymes and m-calpain, and the effects of zinc chloride. Journal of Animal Science, 69, 4449-4460.

Yamashita, M., \& Konagaya, S. (1990a). Purification and characterization of cathepsin B from the white muscle of chum salmon, Oncorhynchus keta. Comparative Biochemistry and Physiology, 96B(4), 733-737.

Yamashita, M., \& Konagaya, S. (1990b). Purification and characterization of cathepsin L from the white muscle of chum salmon, Oncorhynchus keta. Comparative Biochemistry and Physiology, 96B(2), 247-252. 
Figure 1: SDS-PAGE followed proteolysis of sarcoplasmic proteins by m-calpain for $2 \mathrm{~h}$ (lanes 2 to 4 ) followed by cathepsins mixture (lanes 5 to 8). A: combined experiment with mcalpain and cathepsins, B: treatment without cathepsins, C: treatment without m-calpain, D: control without any enzyme. Lanes 1 and 9: SDS-6H and SDS-7 molecular weight markers. Lane 2: initial reaction mixture at time 0 after the addition of the calpain, lane 3: reaction mixture after $30 \mathrm{~min}$ incubation, lane $4: 1.5 \mathrm{~h}$ incubation, cathepsins were added and sample was withdrawn at $2 \mathrm{~h}$ of total incubation (lane 5), lane 6: $3 \mathrm{~h}$ total incubation, lane 7: $5 \mathrm{~h}$, lane 8: $20 \mathrm{~h}$.

Treatment A

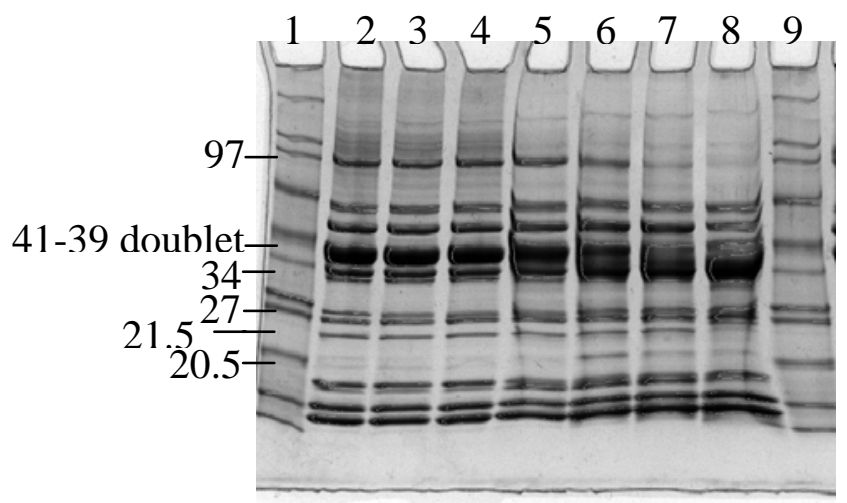

Treatment C

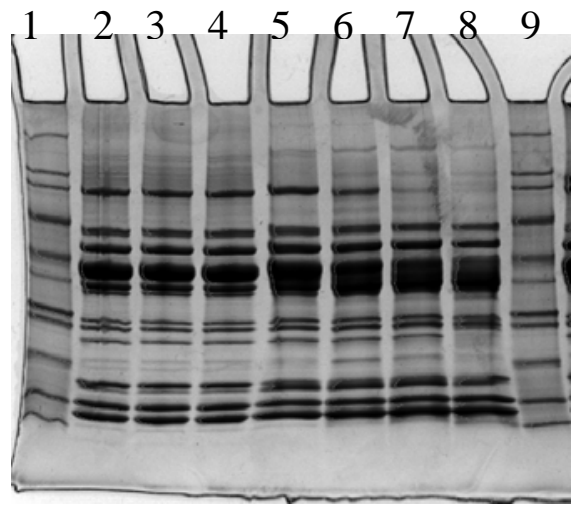

Treatment B

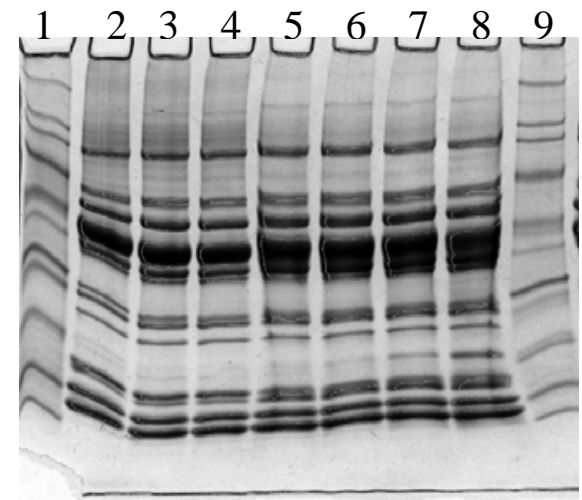

Negative control

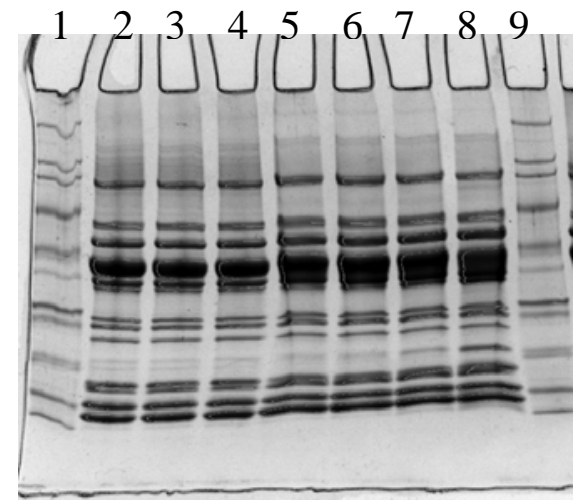


Figure 2: $\alpha$-actinin on Western blots of sarcoplasmic proteins digested during the combined experiment in the presence of $\mathrm{m}$-calpain and cathepsin mixture. Lane 1: initial reaction mixture at time 0 after the addition of the calpain, lane 2: reaction mixture after $30 \mathrm{~min}$ incubation, lane 3: $1.5 \mathrm{~h}$ incubation, cathepsins were added and sample was withdrawn at $2 \mathrm{~h}$ of total incubation (lane 4), lane 5: $3 \mathrm{~h}$ total incubation, lane 6: $5 \mathrm{~h}$, lane 7: $20 \mathrm{~h}$, lane 8: initial sarcoplasmic extract.

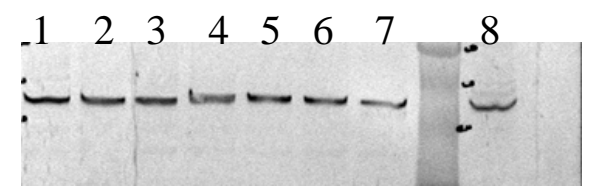

Figure 3: SDS-PAGE analysis of pellet from proteolysis of myofibrillar proteins by m-calpain for $2 \mathrm{~h}$ (lanes 2 to 4 ) followed by cathepsins mixture (lanes 5 to 8). A: combined experiment with m-calpain and cathepsins, B: treatment without cathepsins, $\mathrm{C}$ : treatment without $\mathrm{m}$ calpain, D: control without any enzyme. Lanes 1 and 9: SDS-6H and SDS-7 molecular weight markers. Lane 2: initial reaction mixture at time 0 after the addition of the calpain, lane 3: reaction mixture after 30 min incubation, lane $4: 1.5 \mathrm{~h}$ incubation, cathepsins were added and sample was withdrawn at $2 \mathrm{~h}$ of total incubation (lane 5), lane 6: $3 \mathrm{~h}$ total incubation, lane 7: 5 h, lane 8: $20 \mathrm{~h}$.

Treatment A

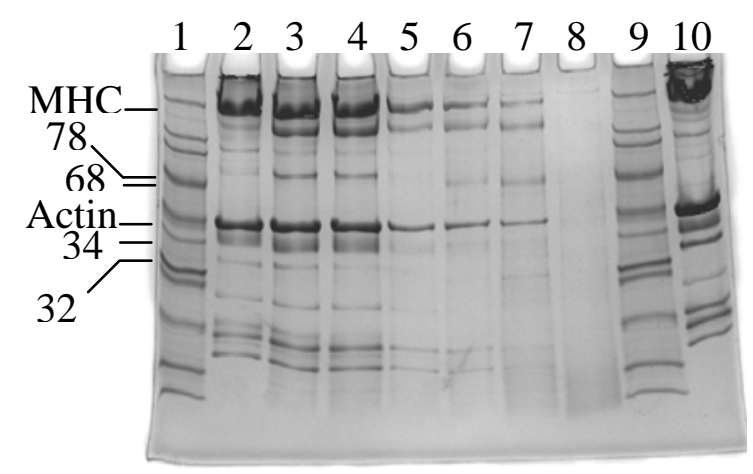

Treatment C

$\begin{array}{llllllllll}1 & 2 & 3 & 4 & 5 & 6 & 7 & 8 & 9 & 10\end{array}$

\section{Treatment B}

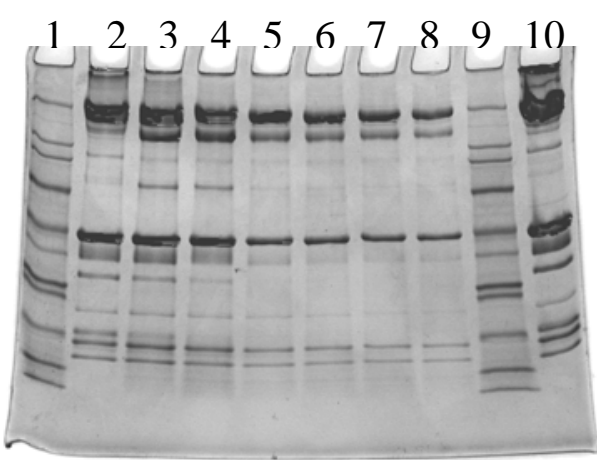

Negative control

$\begin{array}{llllllllll}1 & 2 & 3 & 4 & 5 & 6 & 7 & 8 & 9 & 10\end{array}$ 

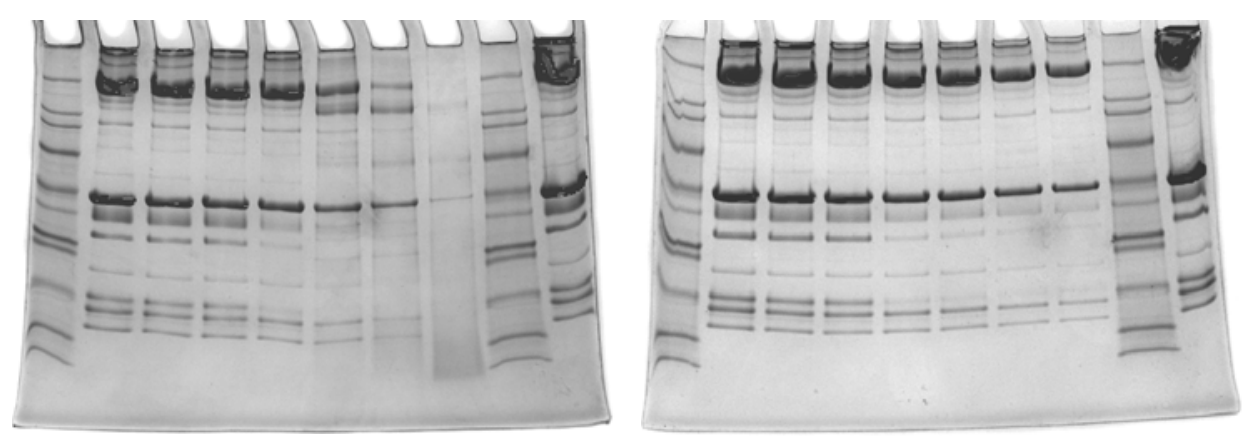

Figure 4: SDS-PAGE and immunoblots of pellet during myofibrillar protein digestion in the combined experiment i.e. treatment $A$ in the presence of m-calpain (lanes 2 to 4 at $0,30 \mathrm{~min}$ and $1.5 \mathrm{~h}$ incubation) followed by cathepsins mixture (lanes 5 to 8 at 2, 3, 5 and $20 \mathrm{~h}$ incubation). I: SDS-PAGE stained with Coomassie Blue (identical to Figure 3A). II: $\alpha$-actinin immunoblot. III: tropomyosin immunoblot. IV: desmin immunoblot. Lanes 1 and 9: SDS-6H and SDS-7 markers (see legend to figure 1) for SDS-PAGE or Broad Precision standards for immunoblots. Lane 10: initial myofibrillar extract.
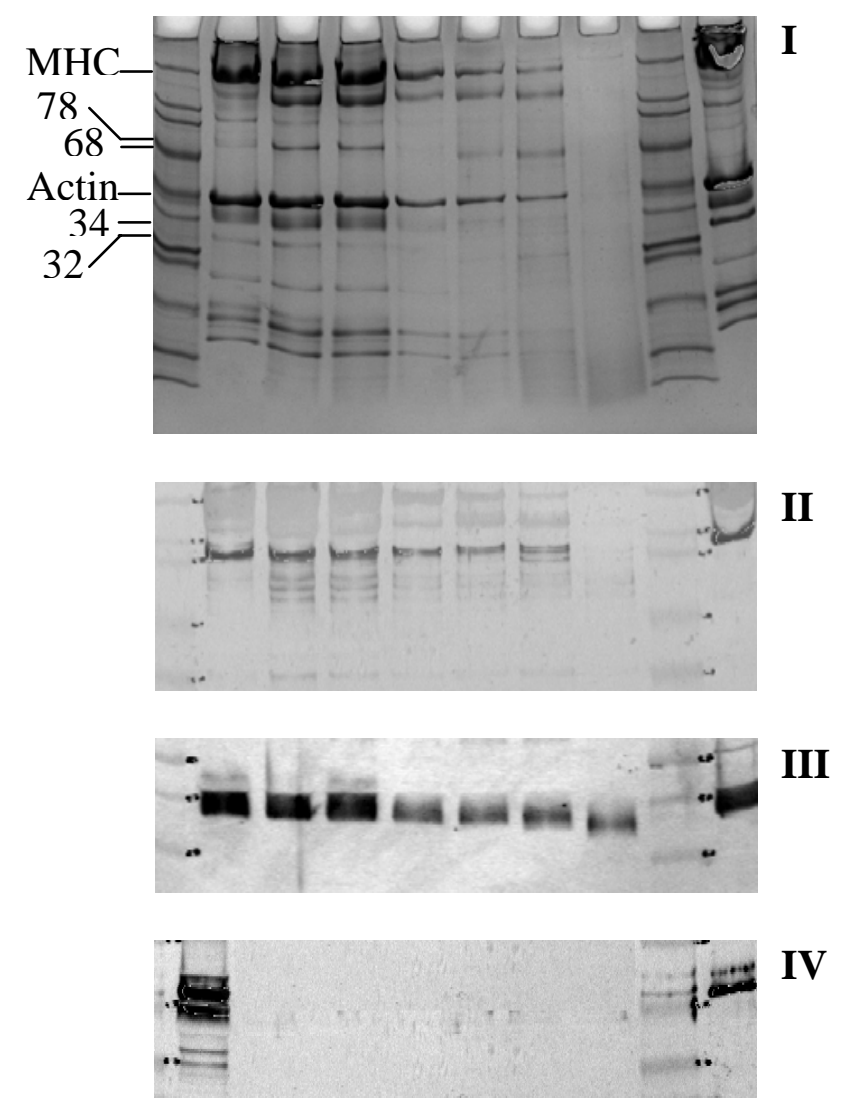
Figure 5: SDS-PAGE and immunoblots of supernatant during myofibrillar protein digestion in the combined experiment i.e. treatment $\mathrm{A}$ in the presence of m-calpain (lanes 2 to 4 at 0,30 min and $1.5 \mathrm{~h}$ incubation) followed by cathepsins mixture (lanes 5 to 8 at 2, 3, 5 and $20 \mathrm{~h}$ incubation). I: SDS-PAGE stained with Coomassie Blue. II: $\alpha$-actinin immunoblot. III: tropomyosin immunoblot. Lanes 1 and 9: SDS-6H and SDS-7 markers for SDS-PAGE and Broad Precision standards for blots..

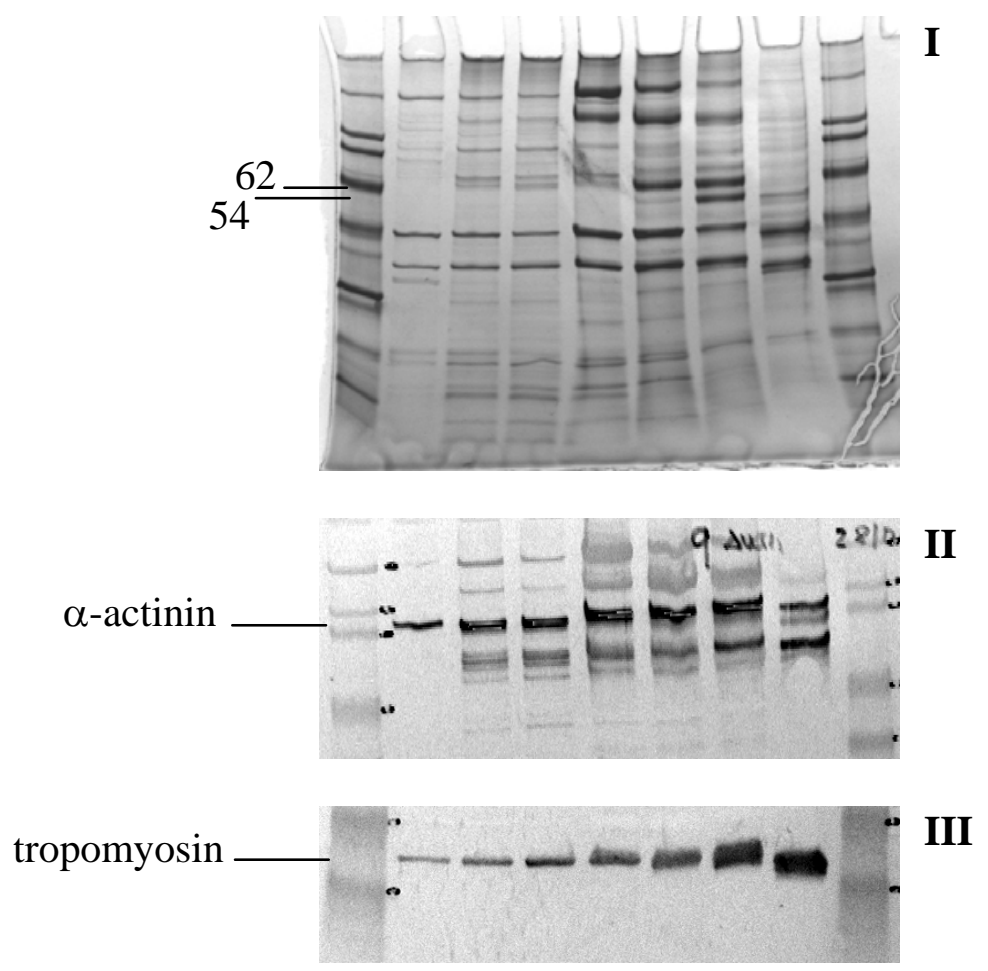

